\title{
XXXVIII. On a method of determining the difference between the phase of two harmonic currents of electricity having the same period
}

\section{Thomas H. Blakesley M.A.}

To cite this article: Thomas H. Blakesley M.A. (1888) XXXVIII. On a method of determining the difference between the phase of two harmonic currents of electricity having the same period, Philosophical Magazine Series 5, 25:155, 295-296, DOI: 10.1080/14786448808628189

To link to this article: http://dx.doi.org/10.1080/14786448808628189

冓 Published online: 29 Apr 2009.

Submit your article to this journal $\pi$

ЏII Article views: 2

Q View related articles $\longleftarrow$ 
both by transverse and longitudinal magnetization in the thermal conducivity, the electrical conductivity, and the thermoelectrical power of the metal, we must be driven to the conclusion that magnetism in all metals exerts two distinct influences; one by rotation of the molecules about their axes, the other in some way which is not yet understood. In such metals as iron, and to a less extent in cobalt and nickel, the first of these influences probably plays a not unimportant part; but in such metals as bismuth, antimony, and tellurium, the second must entirely predominate.

XXXVIII. On a Method of Determining the Difference between the Phase of two Harmonic Currents of Electricity having the same Period. By Thomas H. Blakesley, M.A.*

T $\mathrm{T}$ has been brought to my notice by both English and 1 Foreign journals connected with science that a method of determining the difference in phase of two Harmonic Currents of Electricity having the same period, which I invented and published some years ago, forms an important part of the subject matter of a paper communicated to the Royal Academy of Sciences of Turin, second series, vol. xxxviii., by Signor Galileo Ferraris, in which that philosopher lays claim to the invention above mentioned, producing it as original, with no sign of acknowledgment that the method has before been made public.

The method consists in employing the two coils of an electric dynamometer in a peculiar way. When an harmonic current is sent through the coils of such a dynamometer in series, its reading will measure the quantity $\frac{I^{2}}{2}$, where $I$ is the maximum value of such a current. In this way we may successively determine $\frac{\mathrm{I}_{1}^{2}}{2}$ and $\frac{\mathrm{I}_{2}^{2}}{2}$, where the subscripts refer to two currents having the same period.

But if we place one of the coils in one circuit and the other in the second circuit, the reading of the instrument will measure $\frac{I_{1} I_{2}}{2} \cos \theta$, where $\theta$ is the angle representing the phase-difference of the two currents, to which the name "decalage" has, I have no doubt with great propriety, been accorded by M. Hospitalier.

It is clear that from the three readings we can deduce the

* Communicated by the Physical Society : read March 10,1888. 
angle of phase-difference. Thus, $\alpha_{1}, \alpha_{2}, \alpha_{3}$ being the three readings, we have:-

$$
\begin{aligned}
\alpha_{1} & \propto \frac{I_{1}{ }^{2}}{2}, \\
\alpha_{2} & \propto \frac{I_{2}{ }^{2}}{2}, \\
\alpha_{3} & \propto \frac{I_{1} I_{2}}{2} \cos \theta ; \\
\therefore \cos ^{2} \theta & =\frac{\alpha_{3}{ }^{2}}{\alpha_{1} \alpha_{2}} .
\end{aligned}
$$

Here I have supposed that the same instrument is used successively; and it is hardly necessary to point out that if we have three exactly similar dynamometers, or if we have three dynamometers of which the relative values of the constants are known, we can deduce $\theta$ by means of three simultaneous observations.

The real importance of the determination of the décalage rests in the means it affords us of determining the causes of its existence; among which I may here mention Coefficients of Induction (self or mutual), Capacity of Condensers, and hysteresis or the waste of energy involved in the reversal of electromagnetic momentum, all of which present useful fields for inquiry capable of investigation by means of this application of the dynamometer, a few of which $I$ have myself traversed.

I wish to point out that this method and its importance (not yet fully appreciated) were published by me in the 'Electrician' newspaper of October 2, 1885 ; and the entire series of papers, of which this formed one, was republished in book form at the end of the same year. This was before I had the honour of membership in the Physical Society, or doubtless I should have then brought the subject more immediately under your notice; but upon my being elected a member I lost no time in presenting a copy to this Society, and those who care to examine this question will find therein a chapter devoted to this very employment of the dynamometer to determine Coefficients of Self-and Mutual-Induction and the Capacity of Condensers.

March 1888. 